\title{
Short-time estimation of biogas and methane potentials from municipal solid wastes
}

(Short title: Short-time estimation of biogas produced from MSW)

Sergio Ponsá, Teresa Gea and Antoni Sánchez*

\author{
Department of Chemical Engineering \\ Escola d'Enginyeria, Universitat Autònoma de Barcelona \\ Bellaterra (Cerdanyola del Vallès, 08193-Barcelona, Spain) \\ * Antoni Sánchez: Tel.: 34-935811019; Fax: (34) 93-5812013; E-mail: antoni.sanchez@uab.cat
}

\begin{abstract}
BACKGROUND: Biogas (GB) and methane (BMP) potentials are important parameters to know the energy potential in the anaerobic digestion of municipal solid wastes (MSW) and to design full-scale facilities. However, no standard protocol is defined for this measure.

RESULTS: Several samples of mixed municipal solid waste (MSW) and the source-selected organic fraction of municipal solid waste (OFMSW) obtained at different stages of their mechanical-biological treatment were analyzed. GB and BMP values obtained at different times were correlated. Biogas potentials calculated at $3,4,5,6,7,14,21,50$ and 100 days correlated well for the OFMSW samples. In the case of the MSW samples, only GB values obtained at times of 14 or more days correlated well with the ultimate biogas production (considered at 100 days). The biogas potential analyzed at 21 days proposed in some standard methods accounted for the $77 \%$ of total biogas potential in the OFMSW samples and for the $71 \%$ in the MSW samples, respectively.

CONCLUSIONS: The results are useful for the correct design and operation of anaerobic digestion plants in terms of retention time estimation and to know the expected biogas and methane productions.
\end{abstract}

Keywords: Anaerobic digestion; Biogas; Waste treatment and waste minimization; Characterisation, Process optimisation, Residues.

Pre-print of: Ponsá, S.; Gea, T. and Sánchez, A. "Short-time estimation of biogas and methane potentials from municipal solid wastes" in Journal of chemical technology \& biotechnology (Ed. Wiley), vol. 86, issue 8 (Aug. 2011), p. 1121-1124. The final version is available at DOI 10.1002/jctb.2615 


\section{INTRODUCTION}

Generation of municipal solid wastes (MSW) is a worldwide problem for modern societies. As a consequence of the new regulations, the technologies based on biological treatments to reduce the biodegradable organic matter content of MSW have gained popularity. Among them, anaerobic digestion intended to obtain bioenergy in form of methane, composting or the combination of both in form of mechanical biological treatment plants (MBT) are the most advanced. Besides, since biogas and methane potentials can be considered reliable measures of solid waste biological stability, limits for the final disposal of treated organic wastes based on biogas production have been established or proposed in some European countries such as Germany, ${ }^{1}$ Italy $^{2}$ and England and Wales ${ }^{3}$.

Several studies related to the production of biogas and methane from different organic wastes have been published. In the field of MSW, the main objective of the published works is to determine the potential amount of biogas or methane that can be obtained from anaerobic digestion. ${ }^{4}$ Source-separated collection systems for the organic fraction of MSW have been implemented in different European states. For this reason, the determination of the biogas and methane potentials of these wastes is of special interest. In other published studies, the main objective is to determine the optimal conditions of the biogas production tests. ${ }^{5-7}$ Typically, the duration of these anaerobic tests is often long, which limits their application at industrial scale.

The objective of this research is to study in detail the biogas and methane productions of several samples of MSW from different origins and to obtain a general correlation between biogas and methane productions vs. time. This correlation can be useful for a rapid knowledge of MSW energy potential.

\section{MATERIALS AND METHODS}

\section{Waste samples}

Samples were obtained from different sources to include all the possible range of biogas and methane potentials. Table 1 shows the codification and treatment that correspond to each sample. Fresh (untreated) samples, such as the OFMSW and mixed MSW, were directly obtained from collection trucks. Three 
samples of each fraction were collected from six different municipalities near the city of Barcelona. Treated samples were obtained from a mechanical-biological waste treatment plant located in Barcelona (Spain) with a total capacity of $240,000 \mathrm{Mg}$ per year. ${ }^{8}$ Briefly, the plant operation is divided into three successive units: i) mechanical pretreatment, ii) anaerobic digestion (21 days) and iii) composting (2-4 weeks). The plant processes both the OFMSW and mixed MSW in two independent lines. Treated samples were obtained from different operations as coded in Table 1. Additionally, samples of baled landfilled municipal wastes (aged two years) were also analyzed (MSW-LF) to cover the presumably lowest value of biogas and methane potentials.

Analytical methods and biogas and methane production tests were carried out on a representative sample (approximately $40 \mathrm{~kg}$ ). The sample was obtained by mixing four subsamples of about $10 \mathrm{~kg}$ each, taken from four different points of the bulk of material. Samples were immediately frozen and conserved at $-20^{\circ} \mathrm{C}$ after collection. Before analysis, they were thawed at room temperature during 24 hours.

\section{Biological methane production (BMP)}

There is no a standardized method to determine the BMP and some methods have been proposed. ${ }^{7,9} \mathrm{~A}$ modified method of the protocol described by the German Institute for Standardization reported in the Ordinance on the Environmentally Compatible Storage of Waste from Human Settlements and on Biological Waste-Treatment Facilities ${ }^{1}$ was used because of its simplicity and its wide use as official method in some European countries. This standard test provides the parameter $\mathrm{GB}_{21}$ for the biogas production (GB) expressed as liters of biogas measured under normal conditions produced per $\mathrm{kg}$ of

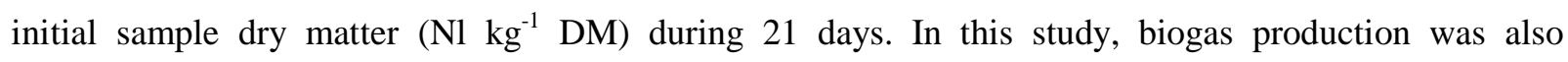
monitored at different times and the test was finished when no biogas production was observed (100 days). The ratio inoculum:substrate used was $0.4: 1$ on dry matter basis and approximately 1:1 on Volatile Solids (VS) basis. No inhibition by the presence of VFA using this inoculum:substrate ratio was observed. This ratio was obtained after previous experiments for the optimization of the method with the wastes studied (data not shown). Inoculum was obtained from the full-scale anaerobic digester of the 
MBT plant (7\% of DM, $90 \%$ of VS on DM basis, $\mathrm{pH}=7.5$ ). All the tests of biogas production were carried out in triplicate. The results are expressed as an average with standard deviation.

The biogas composition was analyzed by gas chromatography to obtain the biochemical methane production (BMP). The details of biogas analysis can be found elsewhere. ${ }^{10}$

\section{Analytical Methods}

Bulk density, water content, dry matter and volatile solids were determined according to the standard procedures. $^{11}$

\section{RESULTS AND DISCUSSION}

\section{Biogas and methane potential of different municipal solid waste samples}

Table 2 shows the values obtained for biogas and biological methane potentials at 21 and 100 days. The dry matter and volatile matter content of the samples are also reported. $\mathrm{GB}_{100}$ for the OFMSW of fresh samples ranged between 270 and $575 \mathrm{Nl}$ biogas $\mathrm{kg}^{-1} \mathrm{DM}_{\text {and }} \mathrm{BMP}_{100}$ values ranged from 150 to $385 \mathrm{Nl}$ $\mathrm{CH}_{4} \mathrm{~kg}^{-1} \mathrm{DM}$. These values are similar to those previously reported by other authors for the total biogas and methane potentials. ${ }^{4} \mathrm{~GB}_{100}$ and $\mathrm{BMP}_{100}$ values obtained for MSW were lower than those of the OFMSW due to the lower volatile and biodegradable matter content in the samples as well as a higher presence of volatile non-biodegradable materials such as plastics in MSW samples.

As observed in Table 2, GB and BMP values gradually decreased at each stage of the waste treatment plant showing the efficiency of the different processes used to stabilize the biodegradable organic matter present in the fresh materials, as it has been recently observed. ${ }^{8}$

\section{Biogas and methane potentials at different periods of time}

From the results presented in the previous section, it can be concluded that the accurate determination of the total biogas or methane potential of an OFMSW or MSW sample requires periods of time of up to 100 days. The disadvantages of such a long analysis are obvious for plant monitoring and design. To 
overcome this problem, values of biogas potential of all the samples obtained at different times were examined to test if a shorter period of time could be representative of the overall biogas production.

Table 3 shows the correlations found for the biogas potential obtained at 3, 4, 5, 6, 7, 14, 21, 50 and 100 days of analysis for the OFMSW samples at different stages of biodegradation. As observed, all GB values correlated well ( $\mathrm{p}$ values below 0.002 in all cases). According to Table 3, $\mathrm{GB}_{14}$ accounts for the $64 \%$ of total biogas potential, $\mathrm{GB}_{21}$ represents the $77 \%$ and $\mathrm{GB}_{50}$ is the $97 \%$, respectively. It is worthwhile to mention that the total biogas and methane production from the OFMSW can be correctly estimated with only 3 days of testing.

In the case of mixed MSW samples (data not shown), the GB values determined after only a few days of analysis did not correlate well with the GB values obtained at longer periods. An explanation of this fact can be the inherent heterogeneity and variability of the composition of these samples. However, GB values tend to be similar at longer experimental times. In this regard, correlations of $\mathrm{GB}_{14}, \mathrm{~GB}_{21}$ and $\mathrm{GB}_{50}$ vs. $\mathrm{GB}_{100}$ are acceptable $(\mathrm{p}<0.01)$. For MSW samples, $\mathrm{GB}_{14}, \mathrm{~GB}_{21}$ and $\mathrm{GB}_{50}$ account for the $38 \%$, $71 \%$ and $94 \%$ of the total biogas potential, respectively. It is particularly remarkable that the value at 14 days is only the $38 \%$ of the total biogas produced, whereas in the case of the OFMSW the biogas produced at 14 days accounted for the $64 \%$ of $\mathrm{GB}_{100}$.

It must be highlighted that the fraction of total biogas potential produced during the same period of time is different for the two different types of wastes considered (OFMSW and MSW), being the disagreement higher for short times of analysis. This fact is interesting since it poses the problem that these materials can behave differently, although no data have been found in literature. Consequently, the amount of biogas produced with time should be investigated for each waste. Besides, from data of biogas production at different times, the retention time could be selected in full-scale anaerobic digestion.

The correlations obtained are valid for all the analyzed samples collected at different stages of biodegradation and can be considered general expressions suitable for process modeling or the estimation of the retention time in a full-scale anaerobic digestion process. 


\section{Acknowledgments}

Financial support was provided by the Spanish Ministerio de Educación y Ciencia (Project CTM200914073-C02-01).

\section{References}

1 German Federal Ministry for the Environment, Nature Conservation and Nuclear Safety, Ordinance on environmentally compatible storage of waste from human settlements and on biological waste$\begin{array}{lllll}\text { treatment facilities of } & 2001 . & \text { February }\end{array}$ http://www.bmu.de/files/pdfs/allgemein/application/pdf/ablagerungsverordnung.pdf (accessed 20 December 2010).

2 Favoino E, The EU legislation and the requirements following for national organic waste management strategies and policies. First Baltic Biowaste Conference, European Compost Network/Organic Recovery and Biological Treatment association (2006). URL: http://www.recestonia.ee/ecn/presentations/2\%20Enzo\%20Favoino.pdf (accessed 20 December 2010).

3 Wagland ST, Tyrrel SF, Godley AR, Smith, R, Test methods to aid in the evaluation of the diversion of biodegradable municipal waste (BMW) from landfill. Waste Manage 29:1218-1226 (2009).

4 Francois V, Feuillade G, Skhiri N, Lagier T, Matejka G, Indicating the parameters of the state of degradation of municipal solid waste. J Hazar Mat 137:1008-1015 (2006).

5 Hansen TL, Schmidt JE, Angelidaki I, Marca E, Jansen JC, Mosbæk H, Christensen TH, Method for determination of methane potentials of solid organic waste. Waste Manage 24:393-400 (2004).

6 Raposo F, Banks CJ, Siegert I, Heaven S, Borja R, Influence of inoculum to substrate ratio on the biochemical methane potential of maize in batch tests. Process Biochem 41:1444-1450 (2006).

7 Anaerobic Biodegradation, Activity and Inhibition (ABAI) Task Group. Task Group Meeting October 2006. Institute of Environment \& Resources, Technical University of Denmark (2006).

8 Ponsá S, Gea T, Alerm L, Cerezo J, Sánchez A, Comparison of aerobic and anaerobic stability indices through a MSW biological treatment process. Waste Manage 28:2735-2742 (2008).

9 Angelidaki I, Alves M, Bolzonella D, Borzacconi L, Campos JL, Guwy AJ, Kalyuzhnyi S, Jenicek P, van Lier JB. Defining the biomethane potential (BMP) of solid organic wastes and energy crops: a proposed protocol for batch assays. Water Sci Technol 59:927-934 (2009).

10 Fernández A, Sánchez A, Font X, Anaerobic co-digestion of a simulated organic fraction of municipal solid wastes and fats of animal and vegetable origin. Biochem Eng J 26:22-28 (2005).

11 The US Department of Agriculture and The US Composting Council, Test methods for the examination of composting and compost. Houston, TX: Edaphos International (2001). 
Tables

Table 1: Codification and general characteristics of the samples analyzed (in brackets, processing time).

\begin{tabular}{|c|c|}
\hline Sample codification ${ }^{*}$ & Treatment \\
\hline OF1 & None \\
\hline OF2 & None \\
\hline OF3 & None \\
\hline MSW1 & None \\
\hline MSW2 & None \\
\hline MSW3 & None \\
\hline OF-MPT & MPT \\
\hline MSW-MPT1 & MPT \\
\hline MSW-MPT2 & MPT \\
\hline OF-AD1 & MPT + AD (21 days) \\
\hline OF-AD2 & MPT + AD (21 days) \\
\hline MSW-AD & $\mathrm{MPT}+\mathrm{AD}$ (21 days) \\
\hline OF-COM1 & $\mathrm{MPT}+\mathrm{AD}(21$ days $)+\mathrm{COM}$ ( 2 weeks $)$ \\
\hline OF-COM2 & MPT + AD (21 days) + COM (4 weeks) \\
\hline MSW-COM1 & MPT + AD (21 days) + COM (4 weeks) \\
\hline MSW-COM2 & $\mathrm{MPT}+\mathrm{AD}(21$ days $)+\mathrm{COM}$ ( 2 weeks $)$ \\
\hline MSW-COM3 & MPT + COM (3 weeks) \\
\hline MSW-COM4 & MPT + COM (4 weeks) \\
\hline MSW-LF1 & Sanitary landfill (2 years) \\
\hline MSW-LF2 & Sanitary landfill (2 years) \\
\hline
\end{tabular}

*Codification used: OF: Organic Fraction of Municipal Solid Waste; MSW: Municipal Solid Waste; MPT: Mechanical Pretreatment; AD: Anaerobic Digestion; COM: Composting; LF: Sanitary Landfill. 
Table 2: Biogas (GB) and methane potential (BMP) at 21 and 100 days, organic and dry matter content for the samples analyzed. Note that samples with the same codification but different number are samples of different origin, municipality, collection system and impurities content (not replications of the same sample). Each sample was analyzed in triplicate so data is presented as average with standard deviation.

\begin{tabular}{|c|c|c|c|c|c|c|}
\hline $\begin{array}{c}\text { Sample } \\
\text { codification }\end{array}$ & $\begin{array}{c}\mathrm{GB}_{21} \\
(\mathrm{Nl} \text { biogas kg } \\
\text { (-1 DM) }\end{array}$ & $\begin{array}{c}\mathrm{GB}_{100} \\
\left.\text { (Nl biogas kg }{ }^{-1} \mathrm{DM}\right)\end{array}$ & $\begin{array}{c}\mathrm{BMP}_{21} \\
\left(\mathrm{Nl} \mathrm{CH} \mathrm{kg}^{-1} \mathrm{DM}\right)\end{array}$ & $\begin{array}{c}\mathrm{BMP}_{100} \\
\left(\mathrm{Nl} \mathrm{CH}_{4} \mathrm{~kg}^{-1} \mathrm{DM}\right) \\
\end{array}$ & $\begin{array}{l}\text { Dry Matter } \\
\text { Fraction }\end{array}$ & $\begin{array}{c}\text { Volatile Solids } \\
\text { Fraction }\end{array}$ \\
\hline OF1 & $92 \pm 33$ & $270 \pm 48$ & $50 \pm 18$ & $148 \pm 34$ & $0.33 \pm 0.04$ & $0.87 \pm 0.03$ \\
\hline $\mathrm{OF} 2$ & $410 \pm 60$ & $575 \pm 75$ & $281 \pm 38$ & $385 \pm 54$ & $0.29 \pm 0.06$ & $0.78 \pm 0.03$ \\
\hline $\mathrm{OF} 3$ & $340 \pm 40$ & $372 \pm 37$ & $223 \pm 8$ & $245 \pm 27$ & $0.20 \pm 0.04$ & $0.88 \pm 0.03$ \\
\hline OF-MPT & $224 \pm 92$ & $305 \pm 26$ & $125 \pm 60$ & $170 \pm 19$ & $0.40 \pm 0.06$ & $0.63 \pm 0.03$ \\
\hline OF-AD1 & $22 \pm 7$ & $51 \pm 11$ & $15 \pm 4$ & $32 \pm 11$ & $0.37 \pm 0.02$ & $0.50 \pm 0.02$ \\
\hline OF-AD2 & $98 \pm 3$ & $152 \pm 5$ & $59 \pm 2$ & $92 \pm 3$ & $0.26 \pm 0.02$ & $0.47 \pm 0.02$ \\
\hline OF-COM1 & $33 \pm 12$ & $68 \pm 12$ & $20 \pm 8$ & $41 \pm 9$ & $0.48 \pm 0.01$ & $0.47 \pm 0.01$ \\
\hline $\mathrm{OF}-\mathrm{COM} 2$ & $48 \pm 3$ & $80 \pm 5$ & $28 \pm 2$ & $48 \pm 3$ & $0.49 \pm 0.01$ & $0.47 \pm 0.02$ \\
\hline MSW1 & $43 \pm 10$ & $129 \pm 50$ & $23 \pm 5$ & $79 \pm 48$ & $0.39 \pm 0.02$ & $0.86 \pm 0.04$ \\
\hline MSW2 & $156 \pm 29$ & $259 \pm 128$ & $91 \pm 10$ & $142 \pm 82$ & $0.39 \pm 0.02$ & $0.69 \pm 0.05$ \\
\hline MSW3 & $89 \pm 7$ & $128 \pm 18$ & $40 \pm 3$ & $66 \pm 12$ & $0.47 \pm 0.02$ & $0.57 \pm 0.01$ \\
\hline MSW-MPT1 & $221 \pm 53$ & $292 \pm 57$ & $130 \pm 8$ & $174 \pm 34$ & $0.30 \pm 0.07$ & $0.75 \pm 0.02$ \\
\hline MSW-MPT2 & $133 \pm 20$ & $207 \pm 44$ & $82 \pm 12$ & $127 \pm 28$ & $0.57 \pm 0.03$ & $0.50 \pm 0.02$ \\
\hline MSW-AD & $120 \pm 59$ & $209 \pm 90$ & $73 \pm 31$ & $126 \pm 53$ & $0.18 \pm 0.02$ & $0.54 \pm 0.03$ \\
\hline MSW-COM1 & $47 \pm 18$ & $75 \pm 20$ & $27 \pm 8$ & $45 \pm 14$ & $0.49 \pm 0.01$ & $0.33 \pm 0.02$ \\
\hline MSW-COM2 & $64 \pm 24$ & $168 \pm 21$ & $41 \pm 16$ & $105 \pm 12$ & $0.56 \pm 0.01$ & $0.52 \pm 0.02$ \\
\hline MSW-COM3 & $97 \pm 9$ & $129 \pm 15$ & $64 \pm 6$ & $86 \pm 10$ & $0.71 \pm 0.02$ & $0.46 \pm 0.03$ \\
\hline MSW-COM4 & $81 \pm 9$ & $107 \pm 14$ & $54 \pm 6$ & $72 \pm 9$ & $0.83 \pm 0.03$ & $0.48 \pm 0.02$ \\
\hline MSW-LF1 & $73 \pm 30$ & $145 \pm 40$ & $48 \pm 23$ & $92 \pm 25$ & $0.56 \pm 0.03$ & $0.54 \pm 0.06$ \\
\hline MSW-LF2 & $120 \pm 22$ & $206 \pm 36$ & $74 \pm 14$ & $129 \pm 23$ & $0.51 \pm 0.03$ & $0.51 \pm 0.02$ \\
\hline
\end{tabular}


Table 3. Correlations for biogas production obtained at different assay times for samples of the organic fraction of municipal solid waste. All the OFMSW samples analyzed in Table 2 are included in these correlations.

\begin{tabular}{|c|c|c|c|c|c|c|c|c|c|}
\hline $\mathrm{Y} \downarrow \mathrm{X} \rightarrow$ & $\mathrm{GB}_{3}$ & $\mathrm{~GB}_{4}$ & $\mathrm{~GB}_{5}$ & $\mathrm{~GB}_{6}$ & $\mathrm{~GB}_{7}$ & $\mathrm{~GB}_{14}$ & $\mathrm{~GB}_{21}$ & $\mathrm{~GB}_{50}$ & $\mathrm{~GB}_{100}$ \\
\hline & $\mathrm{GB}_{3}$ & $\begin{array}{c}0.79 x+2.06 \\
p<0.0001 \\
R^{2}=0.990\end{array}$ & $\begin{array}{c}0.65 x+3.67 \\
p<0.0001 \\
R^{2}=0.974\end{array}$ & $\begin{array}{c}0.54 x+2.96 \\
p<0.0001 \\
R^{2}=0.973\end{array}$ & $\begin{array}{c}0.52 x+0.77 \\
p<0.0001 \\
R^{2}=0.979\end{array}$ & $\begin{array}{c}0.45 x-7.53 \\
p<0.0001 \\
R^{2}=0.948\end{array}$ & $\begin{array}{c}0.36 x-8.07 \\
p=0.0003 \\
R^{2}=0.905\end{array}$ & $\begin{array}{c}0.31 \mathrm{x}-17.7 \\
\mathrm{p}<0.0001 \\
\mathrm{R}^{2}=0.970\end{array}$ & $\begin{array}{c}0.30 \mathrm{x}-21.6 \\
\mathrm{p}<0.0001 \\
\mathrm{R}^{2}=0.953\end{array}$ \\
\hline & & \multirow[t]{2}{*}{$\mathrm{GB}_{4}$} & $\begin{array}{c}0.82 x+1.68 \\
p<0.0001 \\
R^{2}=0.996\end{array}$ & $\begin{array}{c}0.69 x+0.79 \\
p<0.0001 \\
R^{2}=0.994\end{array}$ & $\begin{array}{c}0.66 \mathrm{x}-1.74 \\
\mathrm{p}<0.0001 \\
\mathrm{R}^{2}=0.992\end{array}$ & $\begin{array}{c}0.57 x-11.6 \\
p<0.0001 \\
R^{2}=0.943\end{array}$ & $\begin{array}{c}0.45 x-10.9 \\
p=0.0008 \\
R^{2}=0.867\end{array}$ & $\begin{array}{c}0.39 \mathrm{x}-23.2 \\
\mathrm{p}=0.0005 \\
\mathrm{R}^{2}=0.938\end{array}$ & $\begin{array}{c}0.37 x-27.9 \\
p=0.0002 \\
R^{2}=0.918\end{array}$ \\
\hline & & & $\mathrm{GB}_{5}$ & $\begin{array}{c}0.84 \mathrm{x}-1.06 \\
\mathrm{p}<0.0001 \\
\mathrm{R}^{2}=0.998\end{array}$ & $\begin{array}{c}0.80 \mathrm{x}-3.92 \\
\mathrm{p}<0.0001 \\
\mathrm{R}^{2}=0.990\end{array}$ & $\begin{array}{c}0.68 \mathrm{x}-15.3 \\
\mathrm{p}=0.0001 \\
\mathrm{R}^{2}=0.928\end{array}$ & $\begin{array}{c}0.53 x-13.5 \\
p=0.0016 \\
R^{2}=0.833\end{array}$ & $\begin{array}{c}0.46 x-28.6 \\
p=0.0012 \\
R^{2}=0.845\end{array}$ & $\begin{array}{c}0.44 x-33.9 \\
p=0.0005 \\
R^{2}=0.887\end{array}$ \\
\hline & & & & $\mathrm{GB}_{6}$ & $\begin{array}{c}0.95 x-3.57 \\
p<0.0001 \\
R^{2}=0.996\end{array}$ & $\begin{array}{c}0.82 x-17.9 \\
p<0.0001 \\
R^{2}=0.948\end{array}$ & $\begin{array}{c}0.64 x-15.7 \\
p=0.0011 \\
R^{2}=0.851\end{array}$ & $\begin{array}{c}0.55 x-32.7 \\
p=0.0002 \\
R^{2}=0.911\end{array}$ & $\begin{array}{c}0.53 x-39.1 \\
p=0.0005 \\
R^{2}=0.888\end{array}$ \\
\hline & & & & & 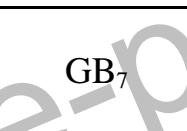 & $\begin{array}{l}0.87 x-16.1 \\
p<0.0001 \\
R^{2}=0.967\end{array}$ & $\begin{array}{c}0.68 x-15.1 \\
p=0.0004 \\
R^{2}=0.891\end{array}$ & $\begin{array}{c}0.56 \mathrm{x}-31.5 \\
\mathrm{p}=0.0001 \\
\mathrm{R}^{2}=0.928\end{array}$ & $\begin{array}{c}0.56 \mathrm{x}-38.2 \\
\mathrm{p}=0.0003 \\
\mathrm{R}^{2}=0.905\end{array}$ \\
\hline & & & & & & $\mathrm{GB}_{14}$ & $\begin{array}{c}0.80 \mathrm{x}-1.06 \\
\mathrm{p}<0.0001 \\
\mathrm{R}^{2}=0.952\end{array}$ & $\begin{array}{c}0.67 x-16.5 \\
p<0.0001 \\
R^{2}=0.939\end{array}$ & $\begin{array}{c}0.64 x-24.4 \\
p=0.0002 \\
R^{2}=0.919\end{array}$ \\
\hline & & & & & & & $\mathrm{GB}_{21}$ & $\begin{array}{c}0.81 \mathrm{x}-13.8 \\
\mathrm{p}=0.0001 \\
\mathrm{R}^{2}=0.928\end{array}$ & $\begin{array}{c}0.77 x-23.1 \\
p=0.0003 \\
R^{2}=0.904\end{array}$ \\
\hline & & & & & & & & $\mathrm{GB}_{50}$ & $\begin{array}{c}0.97 x-13.9 \\
p<0.0001 \\
R^{2}=0.997\end{array}$ \\
\hline & & & & & & & & & $\mathrm{GB}_{100}$ \\
\hline
\end{tabular}

